\title{
Turnover Determinants of New Employees in International Hotels
}

\author{
Huang-Wei Su' ${ }^{1}$ Li-Tze Lee ${ }^{2 *}$, Chiang-Ku Fan ${ }^{3}$ \\ ${ }^{1}$ Department of Tourism and Leisure Management, Tung-Fang Design University, Kaohsiung, Chinese Taipei; ${ }^{2}$ Department of Ac- \\ counting and Information, Overseas Chinese University, Taichung, Chinese Taipei; ${ }^{3}$ Department of Risk Management and Insurance, \\ Shih Chien University, Taipei, Chinese Taipei. \\ Email: hweisu@gmail.com, leelitze@ocu.edu.tw, ckfan@ms41.hinet.net
}

Received February 15 ${ }^{\text {th }}$, 2011; revised March 18 ${ }^{\text {th }}$, 2011; accepted April $13^{\text {th }}, 2011$.

\begin{abstract}
The high turnover rates of new employees in the first career year usually forces hotel human resource managers to face difficult dilemmas. This work presents a modified Delphi method and an analytic hierarchy process (AHP) method to objectively select international hotels based on the results of interviews with experts in the field. Analysis results indicate that the experts select the international hotels with the potential highest turnover risk based on the following rank: internal contentment, external contentment, and organization proffer. Moreover, sensitivity analysis surveys weight of the degree of influence with an alternative hierarchy.
\end{abstract}

Keywords: Modified Delphi Method, Analytic Hierarchy Process, Turnover Determinant, International Hotel

\section{Introduction}

Employees are recognized as important organizational asset and ultimately, firms invest considerable capital in the human resources. Organizational cost incurred due to employees quitting their jobs and the subsequent hiring of replacement personnel [1], new-hire training [2], and general costs for administration [3] can be tremendous in terms of personal, work-unit and organizational re-adjust ment $[3,4]$.

High employee turnover rates are a fundamental labor problem in the hotel sector [5]. A shortage of manpower not only affects service performance, it limits our choices for more qualified hotel staff. Furthermore, a shortage of manpower creates high staff turnover and payroll costs. It also results in disruptions in our operations and service standards [6].

It means many hotel employees terminate their job in their first year. The high employee turnover rate in the first career year usually forces a hotel to face difficult dilemmas. On the one hand, a hotel human resource manager may try to discourage turnover by designing friendly working environment, better benefit, and efficient training programs for their employees. On the other hand, a human resource manager may face the risk the well trained hotel employees will become attractive potential workforce for other hotel competitive [7]. Thus, decreasing employee turnover intention of new employees is an important organizational issue that merits thorough exploration.

To our knowledge, very few turnover determinant studies related to Taiwan hotel employees. This is not surprising since there are severe data limitations in such studies. The main reason is that information on job fluctuations ideally requires examining employees who have turnover intention. In reality, an organizational wide survey may have difficulty to target right employees who have turnover intention and to question them turnover determinants. Fortunately, turnover intentions and actual turnovers were strongly correlated [8]. Such research result presented an interesting alternative for analyzing turnover intention.

The purpose of this study is to search the turnover determinants and categorize them into three criteria: Internal Contentment, External Contentment, and Organizational Proffer, then employ AHP to establish a model for predicting potential turnover risk of international hotels and determine the weights of turnover determinants.

\section{Literature Review}

Based upon theoretical perspective of economy theory and psychology theory, this study identified several determinants of job turnovers. 


\subsection{Determinants of Job Turnovers Based upon Internal Contentment}

Ferres et al. [9] investigated the influence of co-worker trust on selected organizational perceptions and found co-worker trust was a significant predictor of turnover intention. The positive relationship between job strains and turnover intentions was the strongest factor when there was minimal cooperation amongst employees [10]. Practitioners and academics alike have underscored the importance of mentoring because of the benefits that accrue to the subordinates as well as the organization [11-13].

Emotional exhaustion was fond to predict organizational commitment, turnover intentions, and job performance. Most of these relationships remained significant even after taking into account the effects of age, gender, and ethnicity [14]. Another study such as Barsky [15] utilized data from two divergent samples (sales representatives and managers) and employed both self and informant reports of strain measures. They predicted that perceived job stressors would fully mediate the relationship between negative affectivity and turnover intentions.

\subsection{Determinants of Job Turnovers Based upon External Contentment}

Working time may influence job-to-job mobility in a positive manner since lower working hours could imply that a worker is less integrated in a firm [16]. It is also conceivable the long working hours may also increase the desire to change one's job. An inverse relationship between the wage rate and the probability of a job change, which has received the most attention in related literatures, is assumed [17,18]. Other job and employer characteristics such as fringe benefits, flexible working schedules, promotion expectations, firm-specific training, and firm size have been shown to relate to turnover [19] $[20,21]$.

\subsection{Determinants of Job Turnovers Based upon Organizational Proffer}

The literature on the determinants of turnover intention concerning organizational proffer is extremely vast and multifaceted [22,23]. Sousa-Poza and Henneberger [8] analyzed job-turnover intentions in 25 countries found that determinants of turnover intentions do vary substantially among countries. However, job satisfaction, job security, and organization commitment are significant in most countries. Meanwhile, in several psychological models of turnover, the factors with regard to career commitment, job commitment, organizational commitment [2], and job satisfaction are considered to be the determinants of turnover intentions. Another social work of Freund's [24] study found that social workers' career commitment had a significant influence on withdrawal intentions and on thinking of quitting the organization.

Using survey data form an occupationally heterogeneous sample of white-collar employees from various organizations, Poon [25] found manipulations of performance ratings arising from personal bias had negative effects on turnover intention and job satisfaction.

Chen et al. [26] claimed that the larger the gap, the higher the levels of turnover intentions. Another study by Joiner et al. [27] proposed that the mentoring process could serve both career enhancement and psycho-social functions for the subordinates. Career enhancement roles in mentoring include sponsorship, coaching, exposure, protection and provision of challenging assignments. The psycho-social functions include acceptance, counseling, emotional support and role modeling [28].

Literature regarding turnover intention suggested that conditions of employment (e.g. career opportunities) were important causes of turnover intention [29]. When employees considered their career opportunities within the organization as limited or absent, a withdrawal reaction might be evoked in order to cope with the frustrations [30].

\section{Methodology}

In addition to adopting the modified Delphi method to accumulate Subject Matter Expert (SME) opinions and identify a normal evaluation criterion, this study also utilizes the AHP theory to establish a model for predicting potential turnover risk of international hotels.

Turnover determinants of new employees of international hotels must be selected effectively, systematically and objectively to facilitate human resources managers in decision making. Therefore, the Delphi method is adopted to enable SMEs to reach consensus efficiently, subsequently providing administrators with an objective means of predicting potential turnover risk of international hotels.

As a decision-making method that decomposes a complex multicriteria decision problem into a hierarchy [31], Analytic Hierarchy Process (AHP) is also a measurement theory that priorities the hierarchy and consistency of judgmental data provided by a group of decision makers. AHP incorporates the evaluations of all decision makers into a final decision, without having to elicit their utility functions on subjective and objective criteria, by pair wise comparisons of the alternatives [32].

\section{Results}

\subsection{Decision Model Application}

The estimation model in this study consists of two phases. 
The first phase includes four steps, in which the appropriate evaluation criterion is identified using the modified Delphi method. The second phase includes six steps, in which the weight of the decision evaluation criterion is calculated and the suitability of the international hotels model is evaluated-both by using the AHP theory. The phases are described in detail as follows.

\subsubsection{First Phase: Select the Evaluation Criterion through the Modified Delphi Method}

Step 1: Designate the group of human resource SMEs in hotel business.

Nine human resources managers of international hotels are selected to comprise the group of SMEs under the condition that each SME has: (a) at least 10 years of professional experience in the international hotel business sector, and (b) participated in the decision-making process of selecting turnover determinants of new employees in international hotels.

Step 2: Review pertinent literature and accumulate relevant documents on hotel employees' turnover determinants assessment.

Accumulate local and overseas research papers on identifying turnover determinants to be considered in the quantitative criteria for the international hotels. The criteria under evaluation correspond to the consensus among the group of SMEs.

Step 3: Use all criteria to add or omit opinions from the group of SMEs.

The Likert 5-point scale is used to determine the criterion weights: A criterion is considered important if its weight surpasses 4 on the scale. Additionally, the criteria for the major turnover determinants under consideration are used when predicting the potential highest turnover risk hotel.

Step 4: Establish an evaluation criteria model to predicting the potential highest turnover risk hotel.

SMEs form the criterion to establish an estimation model for predicting the potential highest turnover risk hotel, in which the modified Delphi method is adopted to reach a consensus among SMEs. A satisfactory criterion is obtained after three rounds of questionnaire surveys (Table 1).

\subsubsection{Second Phase: Determine the Criteria Weight for the Evaluation Criteria of International Hotels by Applying AHP}

Step 1: Establish a hierarchy structure.

Turnover determinants as evaluation factors for new employees in international hotels comprise several levels, including the goal hierarchy, criteria hierarchy, subcriteria hierarchy and alternative hierarchy (Figure 1).

Table 1. Evaluation criteria for new employees in international hotels.

\begin{tabular}{|c|c|c|}
\hline Criteria & Sub-Criteria & References \\
\hline \multirow[t]{3}{*}{ Internal Contentment } & Manager mentoring process for career enhancement and psycho-social for the subordinates (TF12) & [11-13] \\
\hline & Emotional exhaustion or job stressors (TF14) & [14] \\
\hline & Co-worker trust of cooperation amongst employees (TF15) & [9] \\
\hline \multirow[t]{4}{*}{ External Contentment } & Wage rate (TF6) & {$[17,18]$} \\
\hline & Length of working time (TF5) & [16] \\
\hline & Fringe benefits (TF7) & [19] \\
\hline & Training program (TF11) & [26] \\
\hline \multirow[t]{2}{*}{ Organization Proffer } & Career opportunities (TF13) & [29] \\
\hline & Organization commitment, career commitment, and job commitment (TF17) & [22] \\
\hline
\end{tabular}

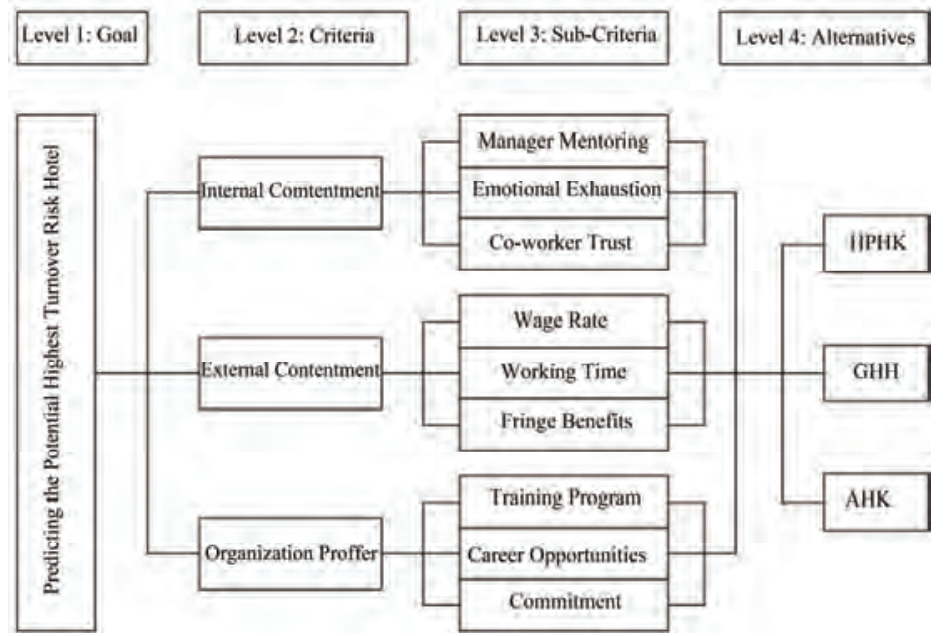

Figure 1. Hierarchical structure to select and evaluate the international hotels. 
Step 2: Establish a pairwise comparison matrix.

Based on the ability of SMEs to assign weight values, the geometric mean value is used to calculate comprehensive decision-making scores from SMEs. In doing so, the standard weight values can be established to predict the potential highest turnover risk hotel. For instance, the main criteria are formed as the sample, as shown in Table 2. Formulae 1 and 2 are used to calculate the aggregate pairwise comparison matrix.

Step 3: Compute the eigenvalue and eigenvector.

The pairwise comparison matrix of the criteria and sub-criteria is used to obtain each hierarchical factor weight, in which the eigenvector is calculated by formula (3) and formula (4). Table 3 summaries those results.

Step 4: Perform the consistency test.

Based on formula (5) and formula (6), the pairwise comparison matrix of consistency is determined for each hierarchy, as shown in Table 2. If the results of the six SMEs in terms of consistency ratio and consensus of CR are smaller than " 0.1 " they conform to principles of consistency.

Step 5: Compute the relative weight of each hierarchy.

Table 3 summarizes the results for the relative weights of the elements for each level. According to this table, the SMEs predict the potential highest turnover risk hotel based on the following rank: Internal Contentment (0.343), External Contentment (0.333), and Organization Proffer (0.323). Evaluation results of the sub-criteria are summarized as Table 3.

Step 6: Calculate the whole level weight to predict the potential highest turnover risk hotel.

In alternative hierarchy level, there are three top Occupancy Rate international hotels in Kaohsiung City [33], including Howard Plaza Hotel Kaohsiung (HPHK), The Ambassador Hotel Kaohsiung (AHK), and The Grand
Hi-Lai Hotel (GHH). The potential highest turnover risk hotel is selected based on the highest score, in the following order: HPH (0.371), GHH (0.362), and AH (0.267), confirming that HPH is the potential highest turnover risk international hotel for new employees, as shown in Table 4.

\subsection{Sensitivity Analysis}

When an advance research is required, Expert Choice software is adopted here to perform sensitivity analysis. Sensitivity analysis can be performed to survey the criterion weight with respect to determining how it influences an alternative hierarchy. A survey is made of how the criteria and sub-criteria weights influence three alternative hierarchies. According to our results for the Dynamic Sensitivity for nodes below Goal, the alternative hierarchy is of the following order: $\mathrm{HPH}, \mathrm{GHH}$, and $\mathrm{AH}$ (Figure 2).

When internal contentment increases form $34.3 \%$ to $60.2 \%$ (Figure 3 ), then the scope of alternative HPH (37.3\%) will be less than alternative GHH (37.4\%). Interestingly, when external contentment increases to $62.4 \%$ (Figure 4), then the scopes of alternative GHH (36.2\%) will be also exceed alternative HPH (36.1\%). That is, when the criteria weight of either internal contentment or external contentment increase continually, the HPH will be substituted by GHH from the best alternative to the second alternative.

The results in Table 4 shows that GHH is rated the highest in criteria such as internal contentment and external contentment. In contrast, HPH proves to be only the most highly rated one for the organization proffer. The circumstance is that the differences among three criteria weights are tiny, that is why HPH is the best choice. Therefore, when the criteria weight of either in-

Table 2. Aggregation of the pairwise comparison matrix for criteria of main criteria.

\begin{tabular}{lccc}
\hline & Internal Contentment & External Contentment & Organization Proffer \\
\hline Internal Contentment & 1 & 1.0303 & 1.0625 \\
External Contentment & 0.9706 & 1 & 1.03125 \\
Organization Proffer & 0.9412 & 0.9697 & 1 \\
\hline
\end{tabular}

$\mathrm{CI}=0.00 ; \mathrm{CR}=0.00<0.1$

Table 3. Weights of criteria and sub-criteria.

\begin{tabular}{|c|c|c|c|c|}
\hline Criteria & Criteria Weights & Sub-Criteria & Sub-Criteria Weights & Weights of over all Levels \\
\hline \multirow[t]{4}{*}{ Internal Contentment } & 0.343 & Manager mentoring process (TF12) & 0.360 & 0.123 \\
\hline & & Emotional exhaustion (TF14) & 0.340 & 0.117 \\
\hline & & Co-worker trust (TF15) & 0.300 & 0.103 \\
\hline & 0.333 & Wage rate (TF6) & 0.396 & 0.132 \\
\hline \multirow[t]{2}{*}{ External Contentment } & & Working time (TF5) & 0.386 & 0.129 \\
\hline & & Fringe benefits (TF7) & 0.218 & 0.073 \\
\hline \multirow{3}{*}{ Organization Proffer } & 0.323 & International hotel (TF11) & 0.397 & 0.128 \\
\hline & & Career opportunities (TF13) & 0.380 & 0.123 \\
\hline & & Organization commitment (TF17) & 0.223 & 0.072 \\
\hline
\end{tabular}




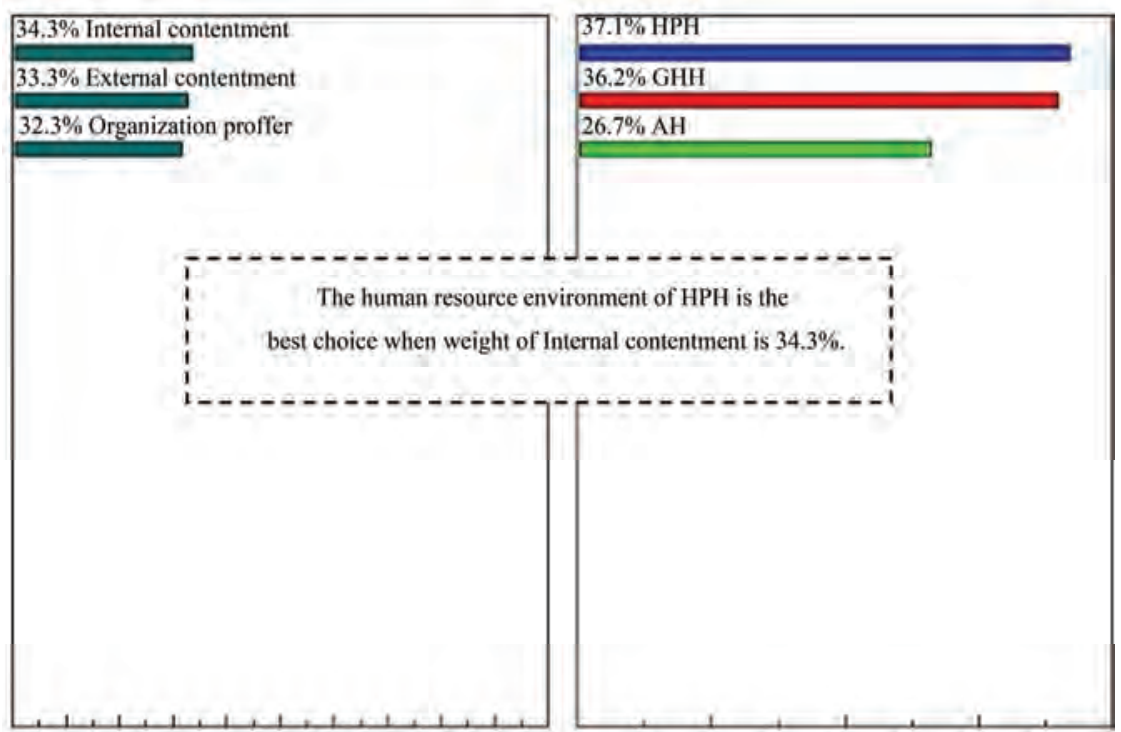

Figure 2. Dynamic sensitivity for nodes below goal.

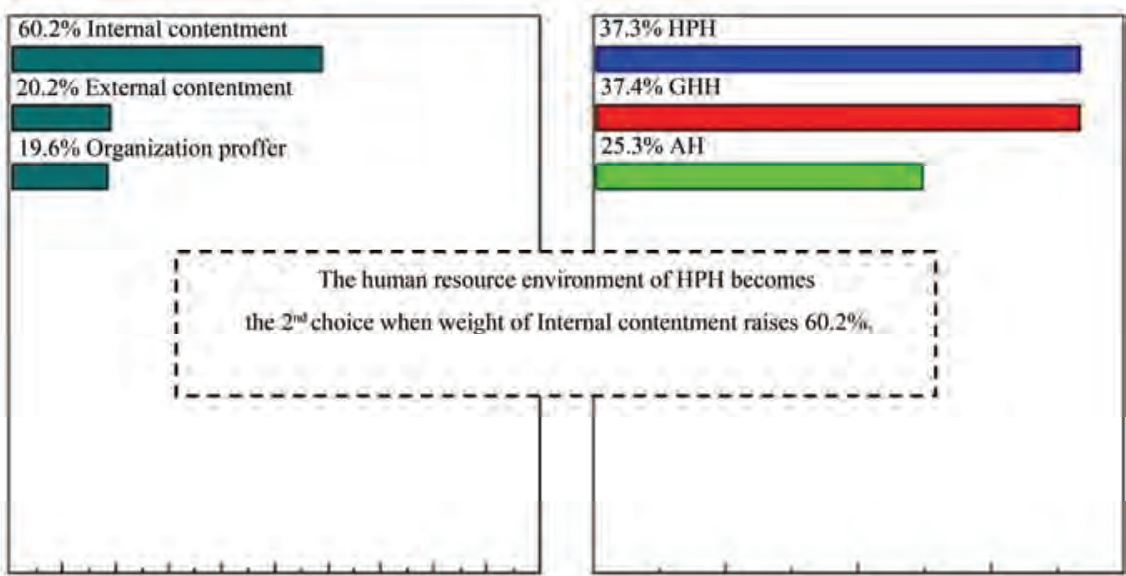

Figure 3. Dynamic sensitivity when internal contentment increases.

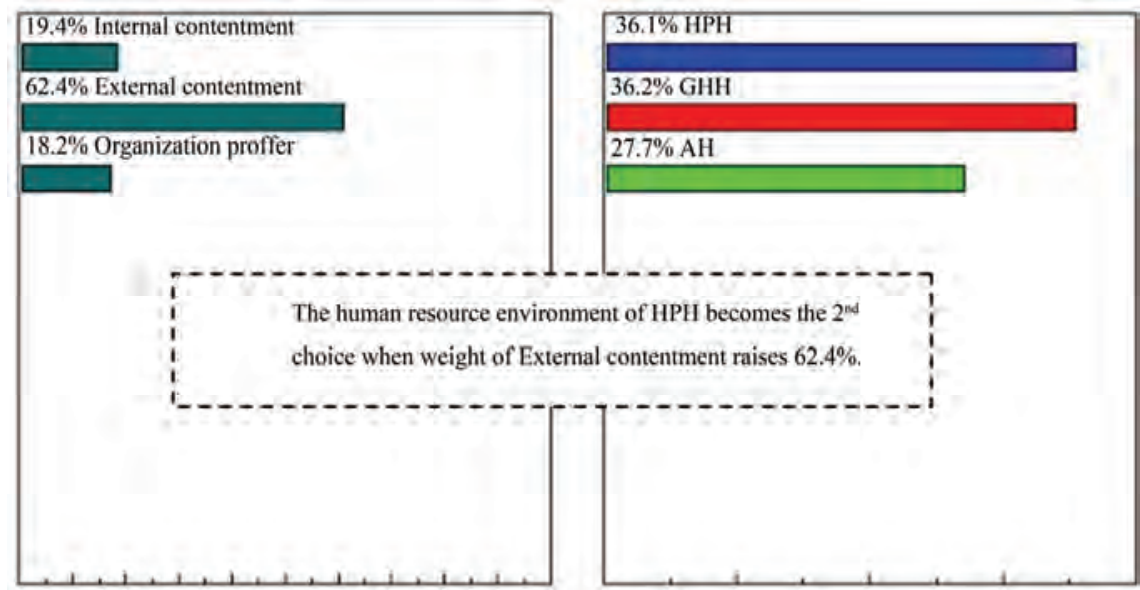

Figure 4. Dynamic sensitivity when external contentment increases. 
Table 4. Hotel rank by AHP model of selection.

\begin{tabular}{ccccc}
\hline Criteria & $\begin{array}{c}\text { Criteria } \\
\text { Weights }\end{array}$ & HPH & GHH & AH \\
\hline Internal contentment & 0.343 & 0.376 & 0.391 & 0.233 \\
External contentment & 0.333 & 0.349 & 0.360 & 0.290 \\
Organization proffer & 0.323 & 0.390 & 0.332 & 0.277 \\
Entirely Sum Score & & 0.371 & 0.362 & 0.267 \\
Rank & & 1 & 2 & 3 \\
\hline
\end{tabular}

ternal contentment is raised higher than $60.2 \%$ or external contentment is raised higher than $62.4 \%$, GHH becomes optimized among these three alternatives.

\section{Conclusions}

Predicting the potential highest turnover risk hotel is often a complicated task. Especially in the rapidly changing economical environment, human resources managers lack precise and objective decision-making procedures and evaluation criteria. Therefore, integrating quantitative methods into the evaluation procedure enables decision makers to identify the potential highest turnover riskinternational hotel objectively and efficiently.

Research results find that SMEs predict the potential highest turnover risk international hotel for the new employees based on the following rank: Internal Contentment (0.343), External Contentment (0.333), and Organizational Proffer (0.323), respectively.

The result from the sensitivity analysis indicates the changing of the criteria weight will result in different alternative ranking. This finding implies the economical environment changing, such as economical tsunami, will lead to a different pursuing goal for new employees. Moreover, the pursuing goal changed means it is the time to update the priority of international hotels.

Finally, the findings in this research demonstrate the effectiveness of the proposed method in predicting the potential highest turnover risk hotel. This study recommends that not only human resources managers but also the other managers in hotel industry can use this model to evaluate and predict the potential highest turnover risk international hotel to strengthen the competition capacity.

\section{REFERENCES}

[1] R. Y. Darmon, "Identifying Sources of Turnover Cost: A Segment Approach,” Journal of Marketing, Vol. 54, No. 2, 1990, pp. 46-56. doi:10.2307/1251869

[2] H. L. Smith and L. E. Watkins, "Managing Manpower Turnover Costs,” Personnel Administrator, Vol. 23, No. 4, 1978, pp. 46-49.

[3] R. W. Griffeth and P. W. Hom, "Employee Turnover," South/Wastern, 2004.

[4] T. W. Lee and T. R. Mitchell, "An Alternative Approach: The Unfolding Model of Voluntary Employee Turnover," Academy of Management Review, Vol. 19, No. 1, 1994, pp. 51-89.

[5] C. Mok and Y. Luk, "Exit Interviews in Hotels: Making them a More Powerful Management Tool,” International Journal of Hospitality Management, Vol. 14, No. 2, 1995, pp. 187-194. doi:10.1016/0278-4319(95)00025-8

[6] Hong Kong Hotels Association, “Chairman's Statement 2009-2010,” 2010.

http://www.hkha.org/internal/hkha_2/news023.htm. 2010

[7] A. Yeung, "Setting People up for Success: How the Portman Ritz-Carlton Hotel Gets the Best from Its People,” Human Resource Management, Vol. 45, No. 2, 2006, pp. 267-275. doi:10.1002/hrm.20108

[8] A. Sousa-Poza and F. Henneberger, "Analyzing Job Mobility with Job Turnover Intentions: An International Comparative Study,” Journal of Economic Issues, Vol. 38, No. 1, 2004, pp. 113-137.

[9] N. Ferres, J. Connell and A. Traraglione, "Co-worker Trust as a Social Catalyst for Constructive Employee Attitude,” Journal of Managerial Psychology, Vol. 19, No. 6, 2004, pp. 608-622. doi:10.1108/02683940410551516

[10] K. J. Harris, M. Janes and R. Boonthanom, "Perceptions of Organizational Politics and Cooperation as Moderators of the Relationship between Job Strains and Intent to Turnover,” Journal of Managerial Issues, Vol. 17, No. 1, 2005, pp. 26-42.

[11] A. Broadbridge, "Mentoring in Retailing: A Tool for Success,” Personnel Review, Vol. 28, No. 4, 1999, pp. 336-355. doi:10.1108/00483489910273651

[12] K. Dansky, “The Effect of Group Mentoring on Career Outcome," Group and Organization Management, Vol. 21, No. 1, 1996, pp. 5-18. doi:10.1177/1059601196211002

[13] L. MacGregor, "Mentoring: the Australian Experience," Career Development International, Vol. 4, No. 5, 2000, pp. 244-249. doi:10.1108/EUM0000000005362

[14] R. Cropanzano, D. E. Rupp and Z. S. Byrne, “The Relationship of Emotional Exhaustion to Work Attitudes, Job Performance, and Organizational Citizenship Behaviors," Journal of Applied Psychology, Vol. 88, 2003, pp. 160-169. doi:10.1037/0021-9010.88.1.160

[15] A. Barsky, C. J. Thoresen, C. R. Warren and S. A. Kaplan, "Modeling Negative Affectivity and Job Stress: A contingency-Based Approach,” Journal of Organizational Behavior, Vol. 25, No. 8, 2004, pp. 915-936. doi:10.1002/job.285

[16] G. Garcia-Serrano, "Worker Turnover and Job Reallocation: The Role of Fixed-Term Contracts," Oxford Economic Papers, Vol. 50, No. 4, 1998, pp. 709-725. doi:10.1093/oep/50.4.709

[17] K. J. Mclaughlin, “A Theory of Quits and Layoffs with Efficient Turnover,” Journal of Political Economy, Vol. 99, No. 1, 1991, pp. 1-29. doi:10.1086/261738

[18] R. E. Hall and E. P. Lazear, "The Excess Sensitivity of Layoffs and Quits to Demand," Journal of Labor Economics, Vol. 2, No. 2, 1984, pp. 233-257. doi:10.1086/298032 
[19] J. Zweimuller and R. Winter-Ebmer, "Firm-Specific Training: Consequences for Job Mobility,” Working Paper, Zurich IEER, 2000, pp. 1-10.

[20] R. Winter-Ebmer and J. Zweimuller, "Firm-size wage differentials in Switzerland: Evidence from Job-changers,” AEA Papers and Proceedings, Vol. 89, No. 2, 1999, pp. 89-93.doi:10.1257/aer.89.2.89

[21] W. Y. Oi and T. L. Idson, “Firm Size and Wages,” In: O. Ashenfelter and D. Card, Eds., Handbook of Labor Economics, Vol. 3, Elsevier, 1999, pp. 2165-2214.

[22] A. Cohn, "The Relationship between Commitment Forms and Work Outcomes: A Comparison of Three Models," Human Relations, Vol. 53, No. 3, 2000, pp. 387-417. doi:10.1177/0018726700533005

[23] J. K. Sager, R. W. Griffeth and P. W. Hom, “A Comparison of Structural Models Representing Turnover Cognitions,” Journal of Vocational Behavior, Vol. 53, No. 2, 1998, pp. 254-273. doi:10.1006/jvbe.1997.1617

[24] A. Freund, "Commitment and Job Satisfaction as Predictors of Turnover Intentions among Welfare Workers," Administration in Social Work, Vol. 29, No. 2, 2005, pp. 5-22. doi:10.1300/J147v29n02_02

[25] J. M. L. Poon, "Effects of Performance Appraisal Politics on Job Satisfaction and Turnover Intention,” Personnel Review, Vol. 33, No. 3, 2004, pp. 322-334. doi:10.1108/00483480410528850

[26] T. Y. Chen, P. L. Chang and C. W. Yeh, “A Study of Career Needs, Career Development Programs, Job Satisfaction, and the Turnover Intentions of R\&D Personnel,”
Career Development International, Vol. 9, No. 4, 2004, pp. 424-437. doi:10.1108/13620430410544364

[27] T. A. Joiner, T. Bartram and T. Gareffa, "The Effects of Mentoring on Perceived Career Success, Commitment and Turnover Intentions," The Journal of American Academy of Business, Vol. 5, No. 1, 2004, pp. 164-170.

[28] K. Cloke and J. Goldsmith, "The Art of Making People Up: Cultivating Awareness and Authenticity at Work," John Wiley \& Sons, New York, 2003.

[29] R. D. Iverson and P. Roy, “A Causal Model of Behavioral Commitment: Evidence from a Study of Australian Blue-Collar Employees,” Journal of Management, Vol. 20, 1994, pp. 15-41. doi:10.1177/014920639402000102

[30] I. Houkes, P. P. M. Jonssen, J. D. Jonge and A. B. Bakker, "Specific Determinants of Intrinsic Work Motivation, Emotional Exhaustion and Turnover Intention: A Multisample Longitudinal Study,” Journal of Occupational and Organizational Psychology, Vol. 76, 2003, pp. 427-450. doi:10.1348/096317903322591578

[31] T. L. Saaty, “The Analytic Hierarchy Process,” McGraw Hill Publications, New York, 1980.

[32] T. L. Saaty, "Decision Making with Dependence and Feedback: The Analytic Network Process,” RWS Publications, Pittsburgh, 1996.

[33] Tourism Bureau. Report on Tourist Hotel Operations in Taiwan, 2010. http://admin.taiwan.net.tw/statistics/month_show_2.asp. 2010 